\title{
Health literacy level of primiparous women with postpartum depression attending to Kabul hospitals, Afghanistan
}

\author{
Zainab Ezadi $^{1}$, Minoor Lamyaian ${ }^{1 *}$, Ali Montazeri ${ }^{2}$ \\ 1. Faculty of Medical Sciences, Tarbiat Modares University, Tehran, Iran \\ 2. Health Metrics Research Center, Iranian Institute for Health Sciences Research, ACECR, Iran
}

Received: 1 September 2021

Accepted for publication: 29 September 2021

[EPub a head of print- 4 October 2021]

Payesh: 2021; 20 (5): 599- 608

\begin{abstract}
Objective(s): Health literacy is an individual and social skill and capacity for access, understanding, processing and evaluation, decision making and behavior regarding medical information and health services. The aim of this study was to investigate the level of health literacy of nulliparous women with postpartum depression attending to Kabul hospitals in Afghanistan.

Methods: A cross-sectional study was performed with a sample of 281 primiparous women in the sixth to eighth weeks after delivery and with the least literacy skills. After obtaining informed consent, the study population completed demographic and fertility questions, the Edinburgh Postpartum Depression Scale adapted to Dari (D-EPDS), and the Dari Health Literacy Instrument for Adults (D-HELIA). The data were analyzed by descriptive and inferential statistical tests.

Results: The mean score of health literacy was 52.21. One hundred and fifty-eight patients (56.2\%) had postpartum depression. The results of multivariate logistic regression showed that postpartum depression significantly was associated with health literacy (OR: 0.95, CI: 0.95-0.99: 95\%, p =0.0001). Also there was significant association between postpartum depression and unwanted pregnancy $(p=0.007)$, age at marriage $(p=0.006)$, unwanted sex of the baby $(p=0.006)$, being abused by the spouse $(\mathrm{p}=0.013)$. There was no statistically significant relationship between postpartum depression and age $(\mathrm{p}=0.08)$, body mass index $(\mathrm{p}=0.21)$, and number of abortions $(\mathrm{p}=0.052)$.

Conclusions: This is the first study that reports on the topic from Kabul-Afghanistan and found that the level of health literacy of primiparous women has a significant relationship with their postpartum depression' It is suggested that educational interventions implemented during pregnancy in order to improve the level of health literacy of primiparous women.
\end{abstract}

Key words: Health Literacy, Postpartum Depression, Primiparous, Kabul

\footnotetext{
${ }^{*}$ Corresponding author: Faculty of Medical Sciences, Tarbiat Modares University, Tehran, Iran

E-mail: lamyianm@modares.ac.ir
} 


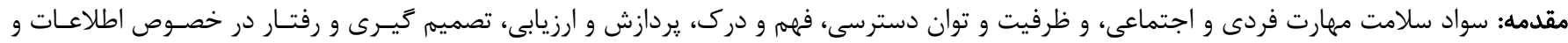

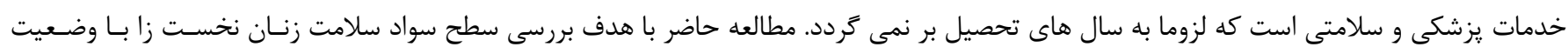

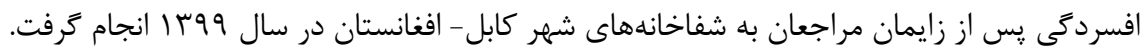

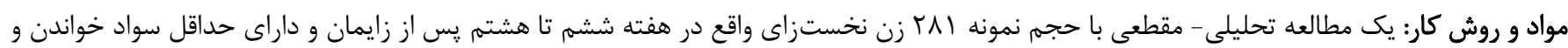

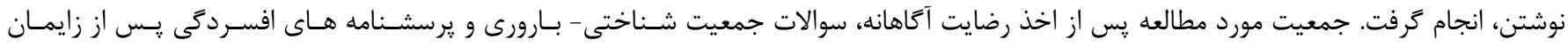

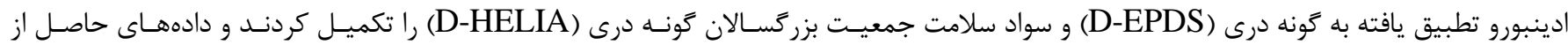

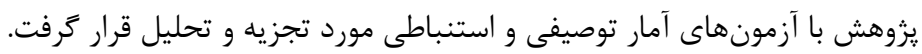

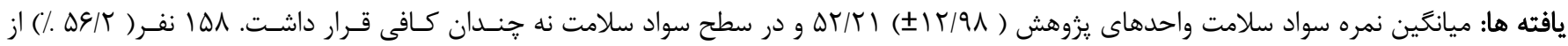

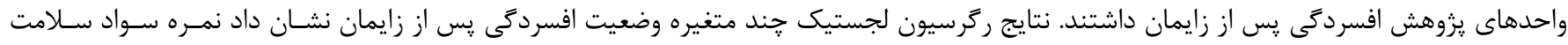

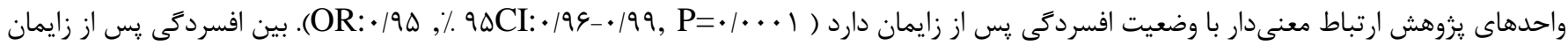

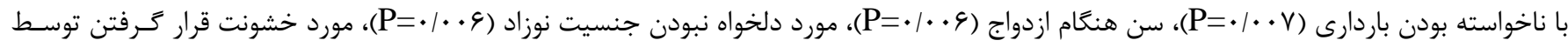

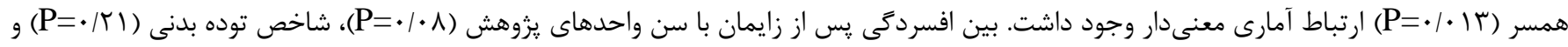

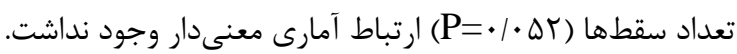

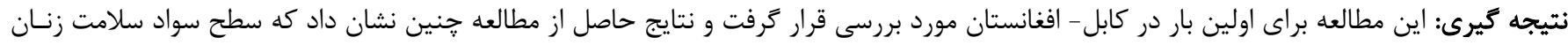

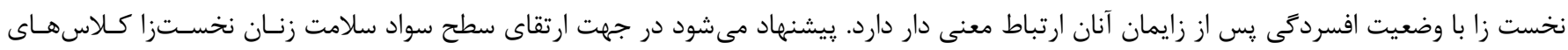
آموزشى در دوران باردارى بركزار كردد.

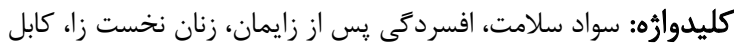
كداخلاق: IR.MODARES.REC.1398.171 


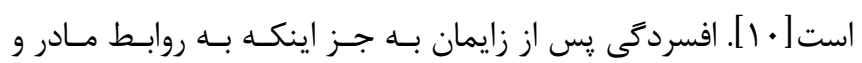

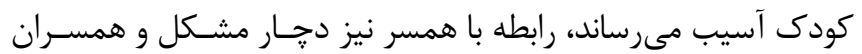

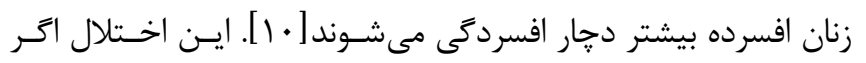

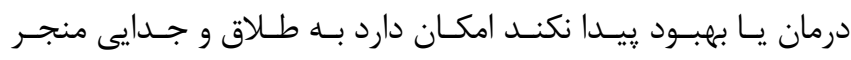

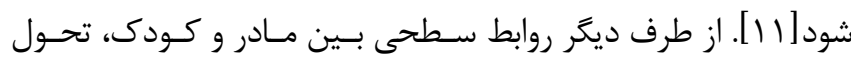

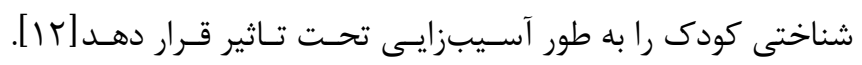

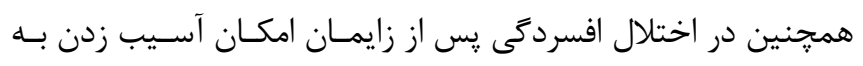

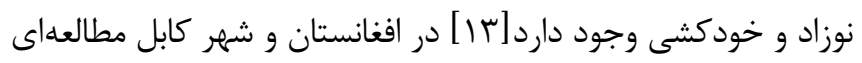

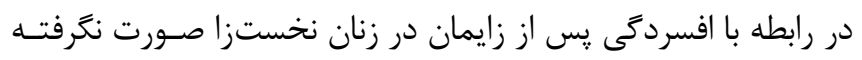

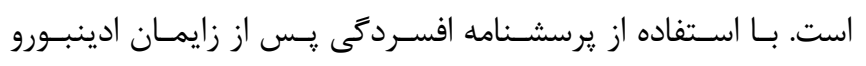

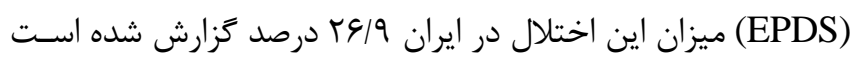

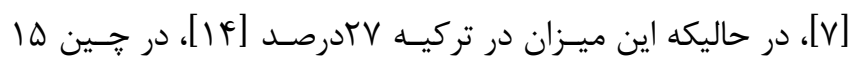

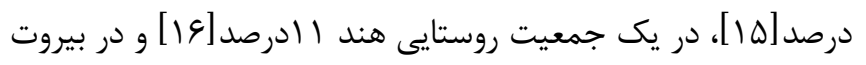

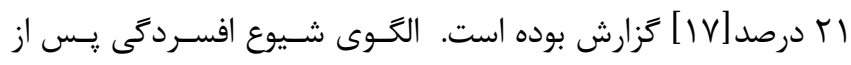

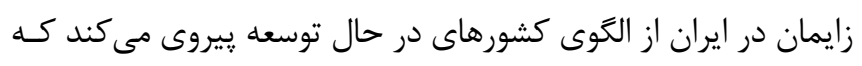

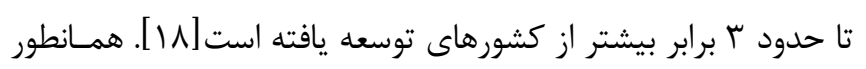

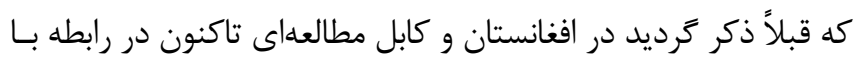

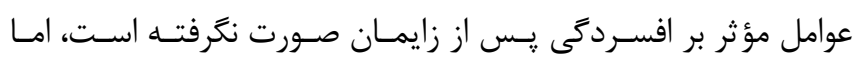

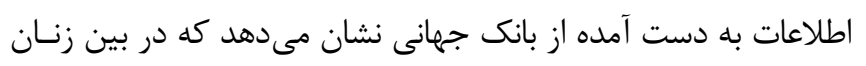

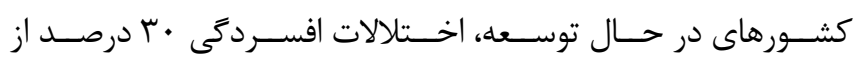

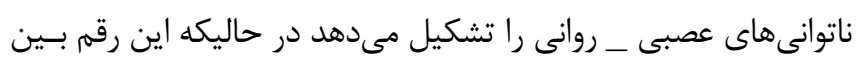

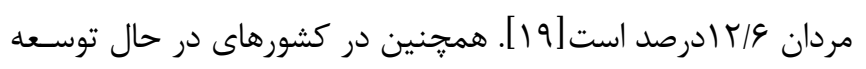

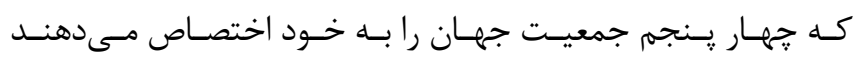

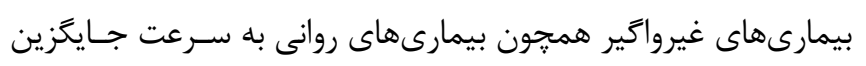

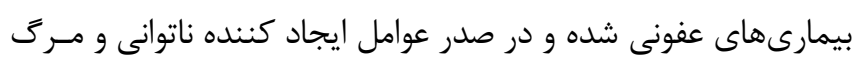

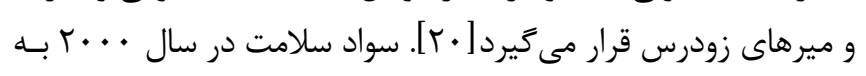

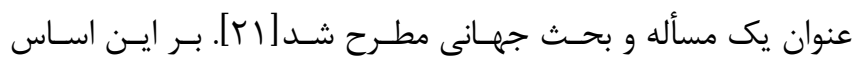

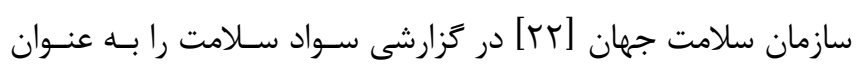

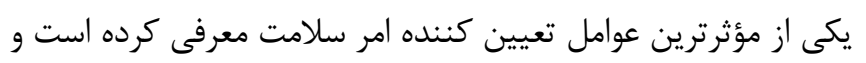

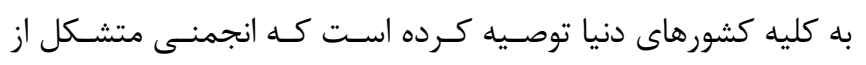

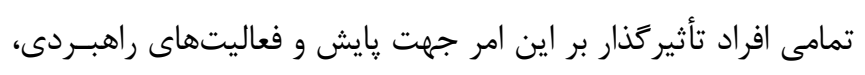

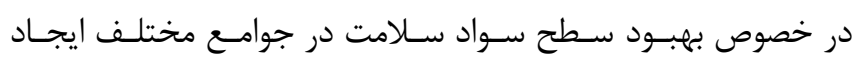

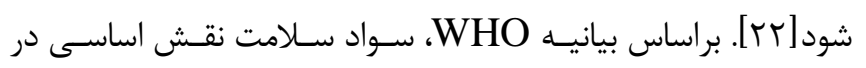

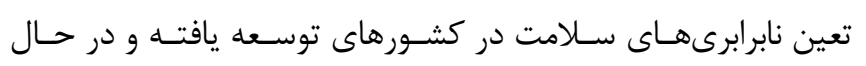

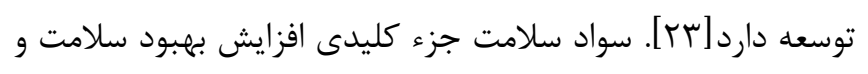

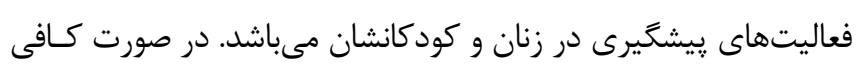

\section{مقدمه - - مقه}

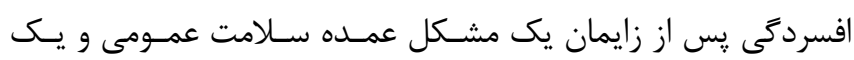

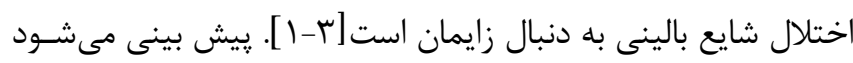

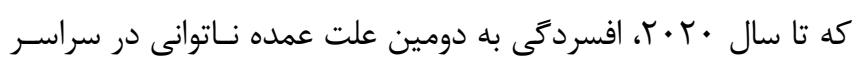

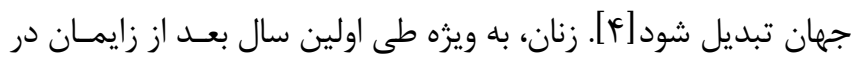

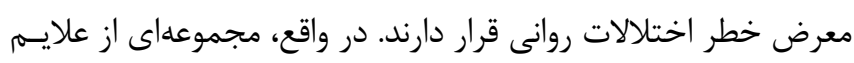

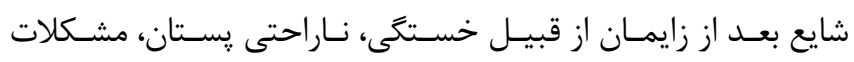

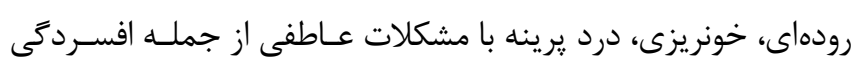

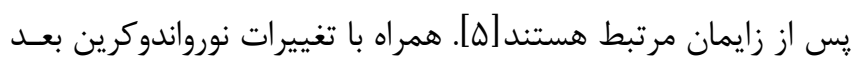

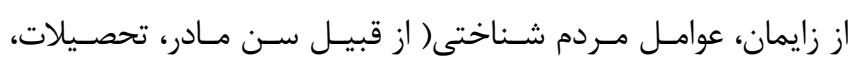

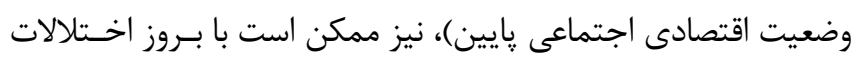

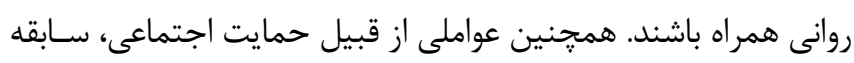

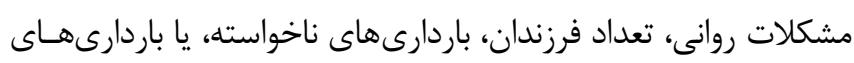

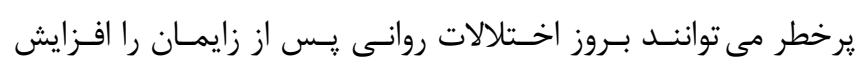

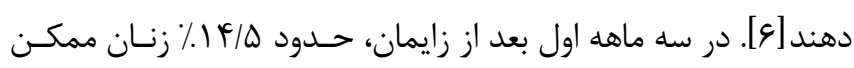

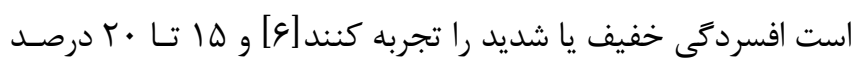

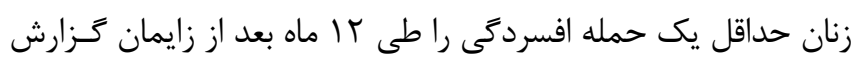

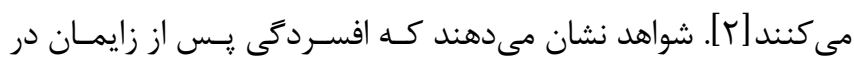

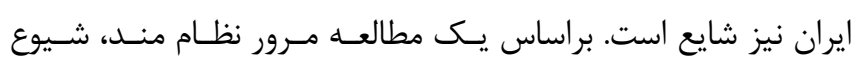

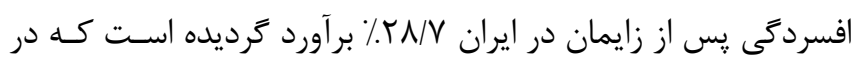

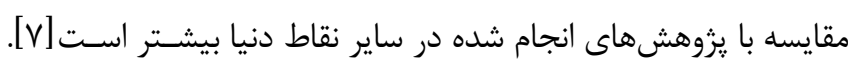

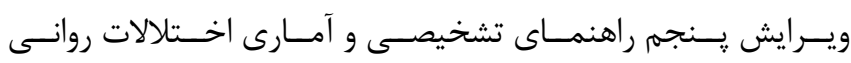
(Diagnostic and Statistical Manual of Mental Disorder/DSM-V) افسردحى يس از زايمان را به عنوان وقـوع افسـردىى اساسى كـه در

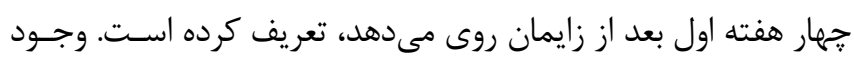

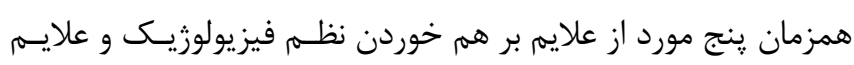

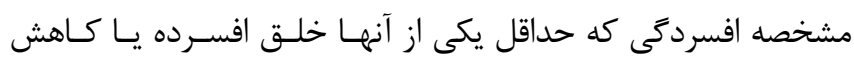

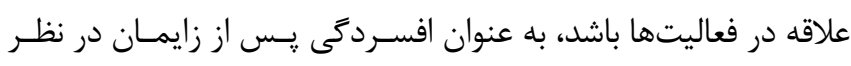

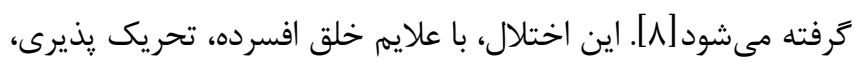

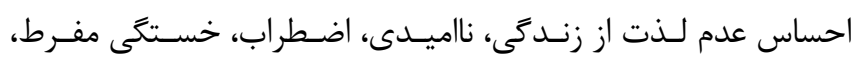

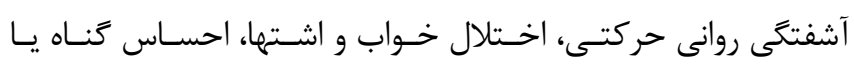

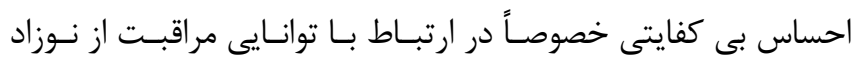

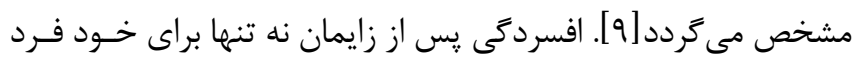

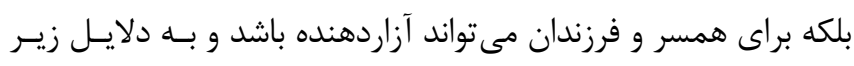

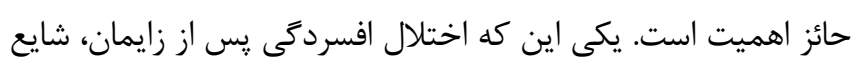

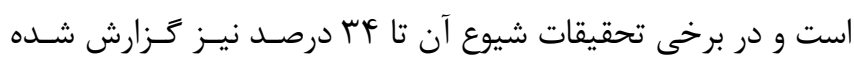




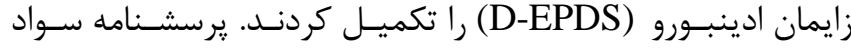

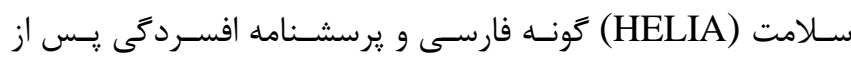

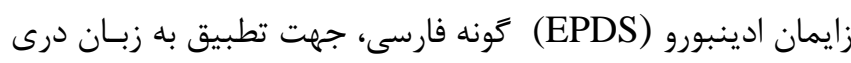

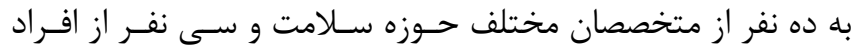

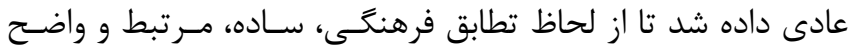

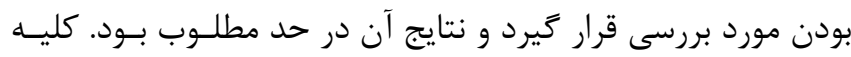

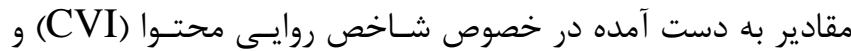

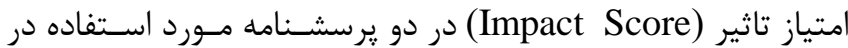

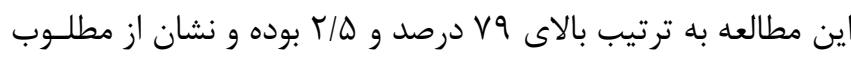
بودن روايى محتوا و روايى صورى آنها داشت.

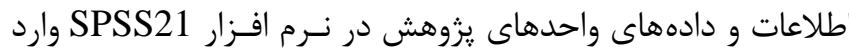

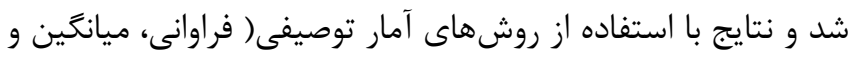

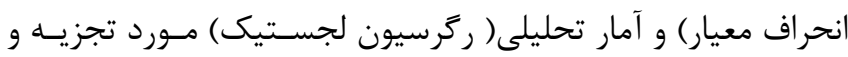

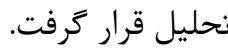

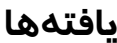

در مجموع INY زئن نخستزا شركت كردند، يافتـه هـاى حاصـل از

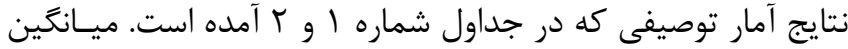

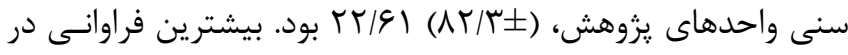
كروه سنى ץY خان خانهار بودند. بيشترين درصد فراوانى سـطح تحصـيلات واحـدهاى

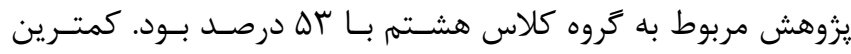
درصد فراوانى با 4/4 درصد متعلق به كروه ليسانس، فوق ليسـانس و كرون

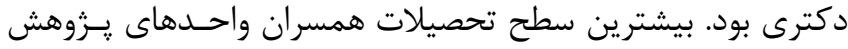

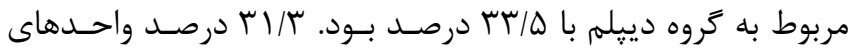

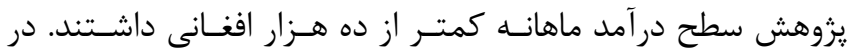

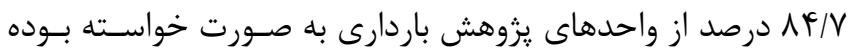

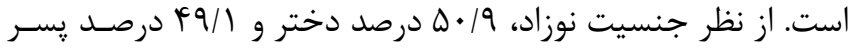

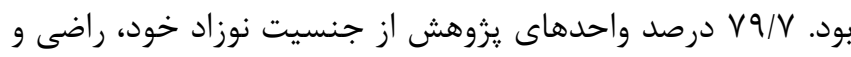

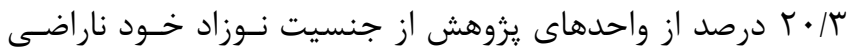

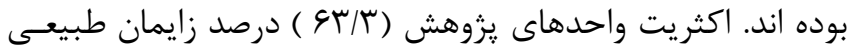

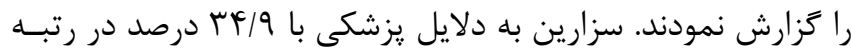

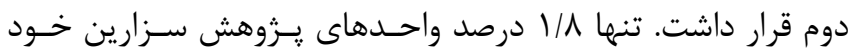

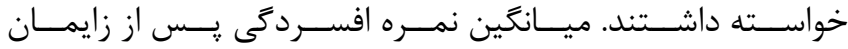
درينبورو(EPDS) واحدهاى يزوهش در هفته ششم تا هشتم يس از

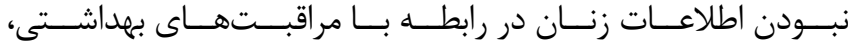
تصميم كيرى هاى آكاهانه براى سلامت خود و خانوادهشان مشـكل يـا

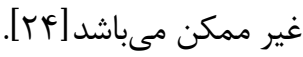

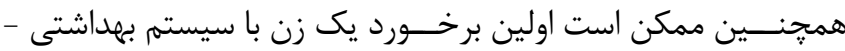

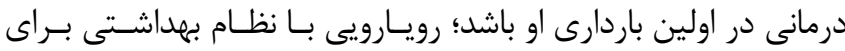

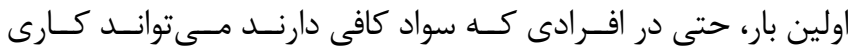

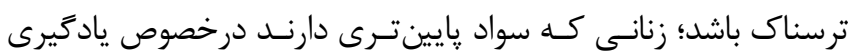

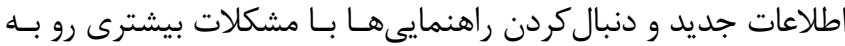

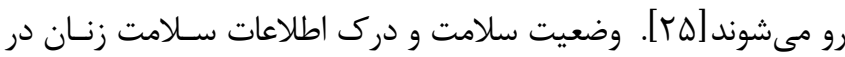

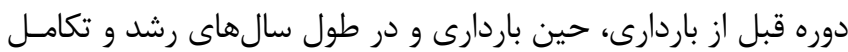
به طور مستقيم كودى را تحت تأثير قرار مى دهد. به دليل تأثير نقش

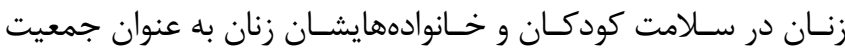

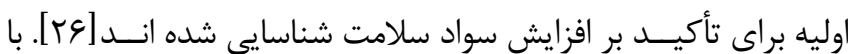
وجود اهميت بسيار زياد امر سواد سلامت در كيفيت زندگى و ارتقاى آنائ

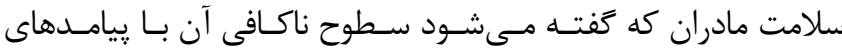

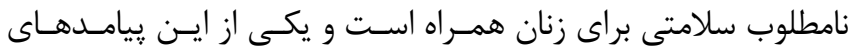

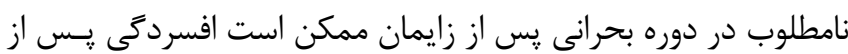
زايمان باشد، در افغانستان تاكنون به اين موضوع يرداخته نشده اسـت إنسات

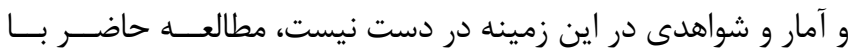

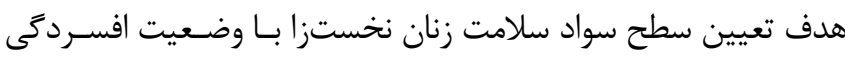
يس إز زايمان در مراجعين به بيمارستانهاى شهر كابـل (افغانسـتان)

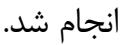

\section{مواد و روش كار}

اين مطالعه از نوع تحليلى - مقطعى است كه با هدف بروستى سـطح

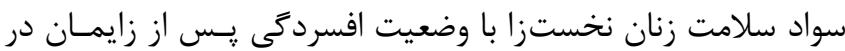

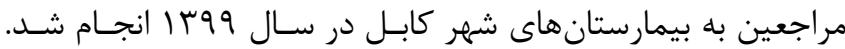

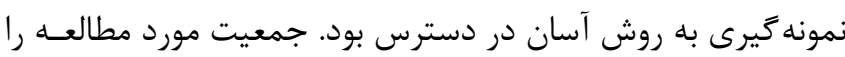
كليه زنان نخستزاى واقع در هفته ششم تا هشتم يس إن زاز زايمان كه

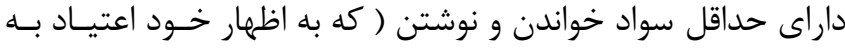
سيكار يا مواد مخدر نداشتند) تشكيل دادند.

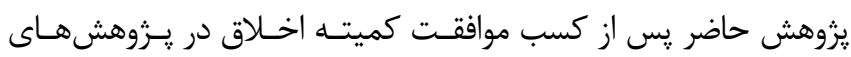
زيست يزشكى IR.MODARES.REC.1398.171، در كشور ايـران و كد اخلاق A.1019.0088 از كشـور افغانسـتان و كسـب رضـايت

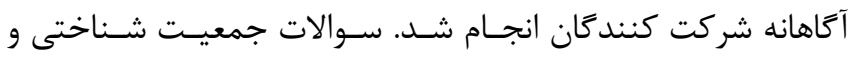

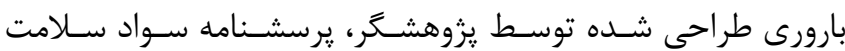

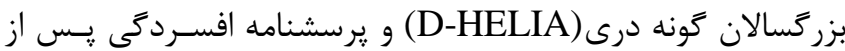


داد، افسردىى يس از زايمان با نمره سواد سلامت واحدهاى يزوهش

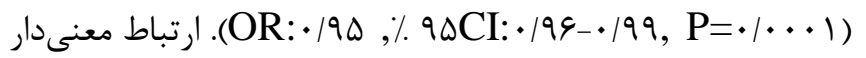

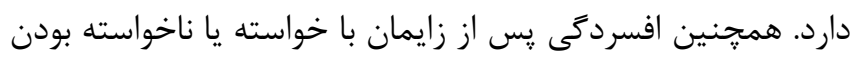

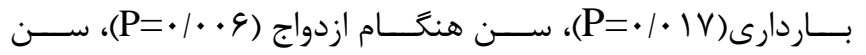

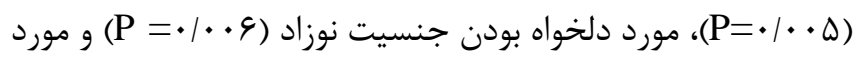

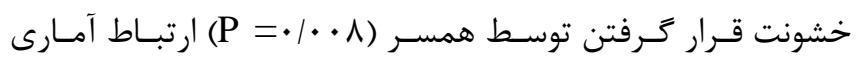

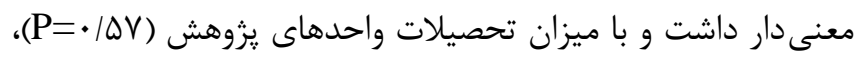

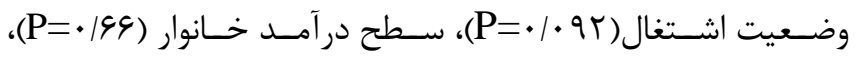
شاخص توده بدنى(ه •(P=1/) ارتباط آمارى معنى دار نداشت.

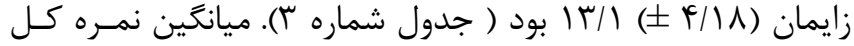
سواد سلامت واحدهاى يزوهش

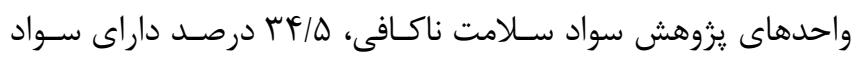

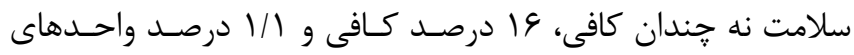

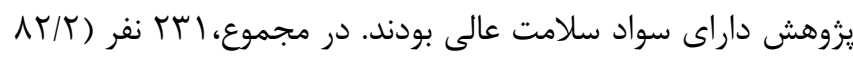

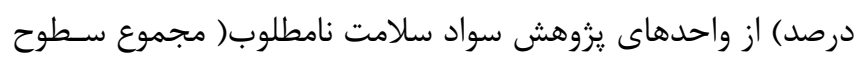

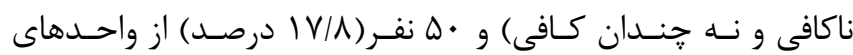

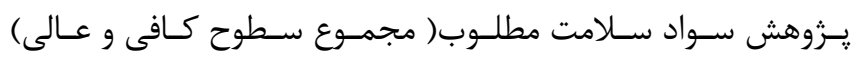

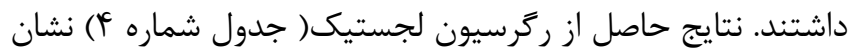

جدول 1: خصوصيات جمعيت شناختى و بارورى واحدهاى يزوهش (N = (NA1)

\begin{tabular}{|c|c|c|}
\hline ل درصد & تعداد & \\
\hline & & رده سنى \\
\hline$V I / T$ & $r \cdot$. & ( \\
\hline$T V / V$ & vı & ( \\
\hline \multirow[t]{2}{*}{$1 / 1$} & $r$ & r \\
\hline & & وضعيت اشتغال \\
\hline$\Lambda \mathrm{V} / \Delta$ & TYG & خانهدار \\
\hline \multirow[t]{2}{*}{$\mid r / \Delta$} & ra & شاغل \\
\hline & & سطح تحصيلات \\
\hline$\Delta r$ & 149 & سيكل \\
\hline$r \cdot / r$ & $\wedge \Delta$ & دييلم \\
\hline $1 \cdot / r$ & rq & فوق دييلم \\
\hline \multirow[t]{2}{*}{$9 / 4$} & 11 & ليسانس و بالاتر \\
\hline & & سطح تحصيلات همسر \\
\hline $11 / v$ & 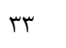 & بى سواد \\
\hline$r v$ & ve & 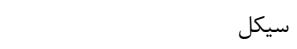 \\
\hline 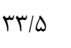 & $q 4$ & دييلم \\
\hline $14 / 9$ & rq & فوق دييلم \\
\hline \multirow[t]{2}{*}{$1 r / 9$} & rq & ل ليسانس و بالاتر \\
\hline & & سطح درآمد ماهانه \\
\hline$r \mid r$ & $\wedge$ & كمتر از ده هزار افغانى \\
\hline $4 \cdot / 9$ & 110 & • ا تا ها هزار افغانى. \\
\hline \multirow[t]{2}{*}{$r V / V$} & vı & ها هزار افغانى به بالا \\
\hline & & خواسته يا ناخواسته بودن باردارى \\
\hline$\Lambda F / V$ & rru & 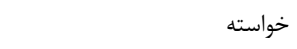 \\
\hline \multirow[t]{2}{*}{$10 / r$} & rr & ناخواسته \\
\hline & & جنسيت نوزاد \\
\hline$\Delta \cdot / 9$ & ler & دختر \\
\hline \multirow[t]{2}{*}{$49 / 1$} & 1 ir & صير \\
\hline & & مورد دلخواه بودن جنسيت نوزاد \\
\hline V৭/v & THF & بلى \\
\hline$r \cdot / r$ & $\Delta V$ & خير \\
\hline & & 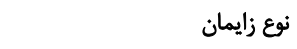 \\
\hline $9 \pi / r$ & IVA & طبيعى \\
\hline $1 / 1$ & $\Delta$ & سزارين خود خواسته \\
\hline$r F / q$ & 91 & سزارين اوررانس \\
\hline
\end{tabular}


If. . سال بيستم، شماره بنجم، مهر - آبان

نشريه يزوهشكده علوم بهداشتى جهاددانشكاهى

جدول r: خصوصيات كمى جمعيت شناختى و بارورى واحدهاى يزوهش(N =rAl)

\begin{tabular}{|c|c|c|c|c|}
\hline حداكثر & حداقل & انحراف معيار & ميانكين & \\
\hline rq & 19 & T/AT & rT/91 & سن \\
\hline ro & 14 & $r / T F$ & $r \cdot / 9$ & سن موقع ازدواج \\
\hline 10 & -1 & $r / 41$ & $\Delta / \Delta \omega$ & اختلاف سنى بين زوجين \\
\hline 4 & $\cdot$ & $\cdot / N T$ & $\cdot / r \Lambda$ & تعداد سقط قبلى \\
\hline$r \Delta / r$. & $1 / / 9 F$ & r/A & TY/AY & شاخص توده بدنى \\
\hline
\end{tabular}

جدول r: ميانكين نمره افسردكى يس از زايمان واحدهاى يروهش (N=rAI)

\begin{tabular}{llll}
\hline نمره افسرد & \\
\hline
\end{tabular}

جدول f: نتايج ركرسيون لجستيك تك متغيره و جند متغيره افسردىى بس از زايمان

\begin{tabular}{|c|c|c|c|c|}
\hline P-Value & $\begin{array}{l}\text { جند متغيره Cl) } \\
\text { OR(95\% }\end{array}$ & P-Value & $\begin{array}{l}\text { تك متغيره } \\
\text { OR(95\% Cl) }\end{array}$ & \\
\hline \multirow[t]{2}{*}{ - IATA } & $1(\cdot / \lambda 11-1 / 11)$ & $\cdot \cdots \Delta$ &.$/ 91(\cdot / \Lambda \Delta F-\cdot / 9 V Y)$ & سن \\
\hline & & & & وضعيت اشتغال \\
\hline--- & --- & .1 .95 & $1 / \Lambda \Delta(\cdot / 9 \cdot \Delta-r / V \Lambda V)$ & شاغل \\
\hline \multirow[t]{2}{*}{---} & --- & --- & $1 / \cdot \cdot$ (ref.) & خانهدار \\
\hline & & & & تحصيلات زن \\
\hline --- & --- & --- & $1 / \cdot$ (ref.) & קنججم \\
\hline --- & --- & $\cdot / / \vee \wedge$ & $r / T \Delta$ & سيكل ل \\
\hline--- & --- & - IVGF & $1 / r$. & دييلم \\
\hline--- & --- & $.1 . \mathrm{FV}$ & $r / \pi 4$ & فوق دييلم \\
\hline \multirow[t]{2}{*}{--- } & --- & $\cdot / \Delta \mathrm{VA}$ & $1 / 4 F$ & ليسانس و بالاتر \\
\hline & & & & تحصيلات همسر \\
\hline --- & --- & $\cdot / 1 \Delta \Delta$ & r/IV & سيكل \\
\hline --- & --- & - /FaF & $\mid / 41$ & دييلم \\
\hline--- & --- & $\cdot 1 \cdot v 9$ & T/IS & فوق دييلم \\
\hline \multirow[t]{2}{*}{---} & --- & $\cdot|r \Delta|$ & $1 / \Delta \Lambda$ & ليسانس و بالاتر \\
\hline & & & & سطح درآمد ماهانه \\
\hline--- & --- & --- & $1 / \cdot \cdot$ (ref.) & زير •ا هزار افغانى \\
\hline--- & --- & $\cdot / V T I$ & $1 / \pi 1$ & F أ- إهزار افغانى \\
\hline --- & --- & $\cdot / A V \Lambda$ & $1 / 1 r$ & 19-19 ا هزار افغانى \\
\hline--- & --- & .1990 & $1 / \pi \Delta$ & • آهزار افغانى و بالاتر \\
\hline --- & --- & $\cdot \pi / \Delta$ & $1 / \cdot \Delta(\cdot / q \gamma \cdot-1 / / \uparrow \Delta)$ & شاخص توده بدنى \\
\hline$\cdot / \cdot v$ & $\cdot / \wedge q(\cdot / \Lambda \cdot \Delta-1 / \cdot \uparrow \Delta)$ & $.1 . .4$ & $\cdot / 1 \Lambda(\cdot / 1 \cdot 9-\cdot / 999)$ & سن هنكام ازدواج \\
\hline \multirow[t]{2}{*}{--- } & --- & $\cdot / V \Delta$ & $1 / \cdot r(\cdot / q \cdot \Delta-1 / 1+q)$ & تفاوت سنى بين زوجين \\
\hline & & & & خواسته يا ناخواسته بودن باردارى \\
\hline --- & --- & --- & $1 / \cdots$ (ref.) & خواسته \\
\hline \multirow[t]{2}{*}{$\cdot / \cdot v$} & $r(\cdot / / 9 \cdot-\cdot / \vee १ 9)$ & $.1 .1 \mathrm{~V}$ & $r / \Delta \Delta(\cdot / / \Lambda T-\cdot / \Lambda F r)$ & ناخواسته \\
\hline & & & & جنسيت نوزاد \\
\hline --- & --- & --- & $1 / \cdot \cdot$ (ref.) & دختر \\
\hline \multirow[t]{2}{*}{--- } & --- & . & $\cdot \mid \operatorname{Ar}(1 / T|-\cdot| \Delta \mid r)$ & 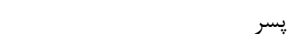 \\
\hline & & & & مورد دلخواه بودن جنسيت نوزاد \\
\hline--- & --- & --- & $1 / \cdot$ (ref.) & 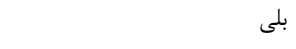 \\
\hline$\cdot / \cdot 1$ & $\cdot / \pi \psi(\cdot / F V G-1 / T \Delta T)$ & $.1 . \cdot 9$ & $\cdot / \cdot \Lambda(\cdot / / 9 \Delta-\cdot / \vee \Delta \Delta \Lambda)$ & خير \\
\hline \multirow[t]{2}{*}{$\cdot 1 \cdot \cdots 1$} &.$/ 9 \Delta(\cdot / 94 \wedge-\cdot / 9 \vee 9)$ & $\cdot 1 \cdot \cdots 1$ & $\cdot / 90(\cdot / 99-\cdot / 99)$ & نمره سواد سلامت \\
\hline & & & & نوع زايمان \\
\hline ---- & --- & --- & $1 / \cdot \cdot$ (ref.) & طبيعى \\
\hline--- & --- &.$/ 94$ & $\cdot / 91(\cdot / \Delta 9-1 / 81)$ & سزارين به درخواست مادر \\
\hline--- & --- &.$/ 14$ & $\cdot / 1 \Lambda(\cdot / \cdot r-1 / V Y)$ & سزارين به دلايل يزشكى \\
\hline
\end{tabular}




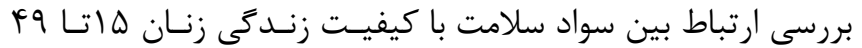

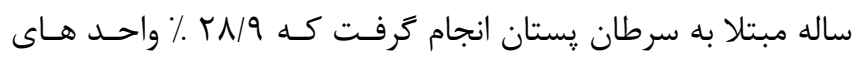

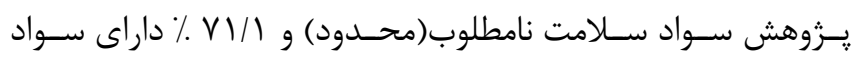

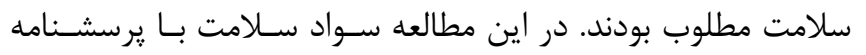

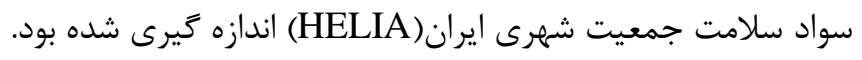

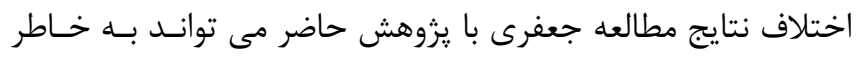

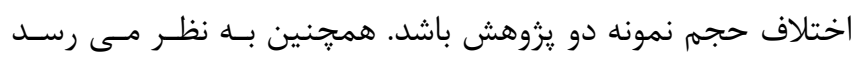

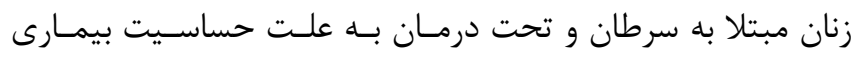

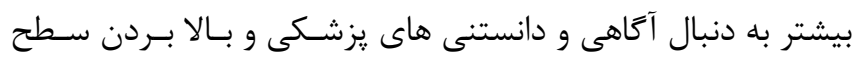
سواد سلامت خود هستند [اسب].

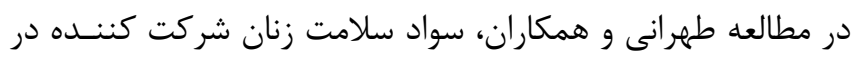

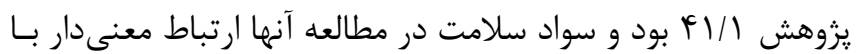

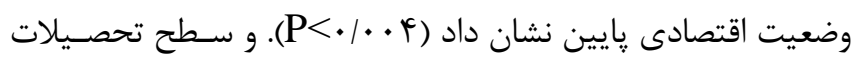

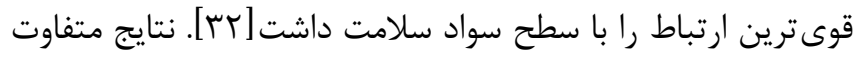

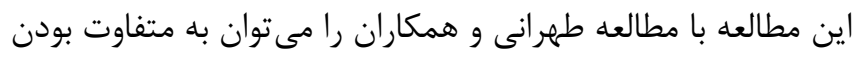

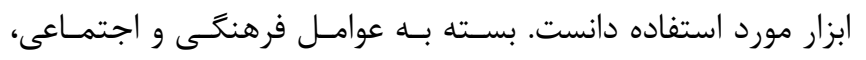

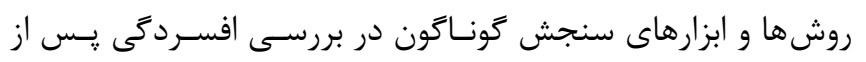

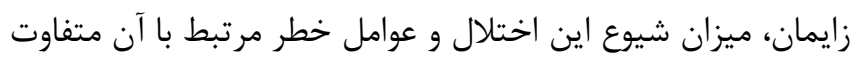

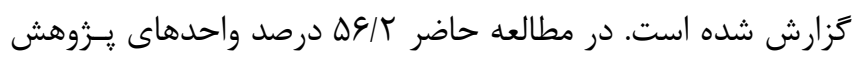

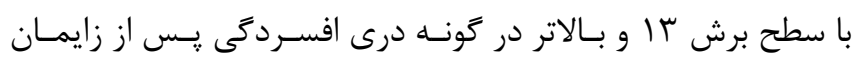

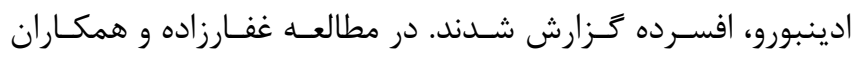

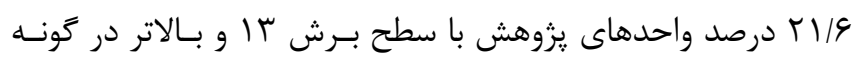

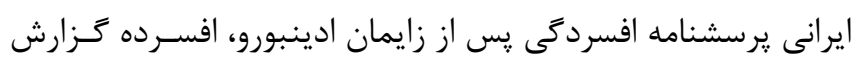

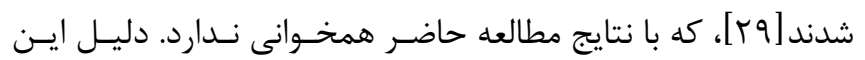

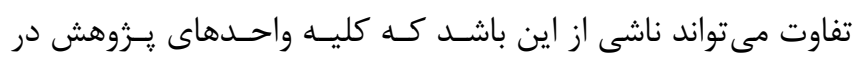

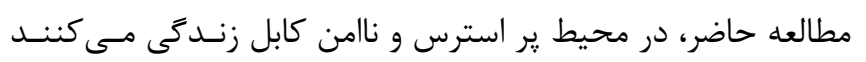

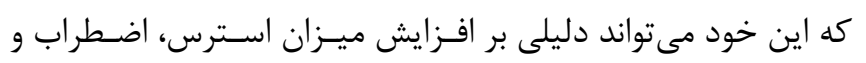

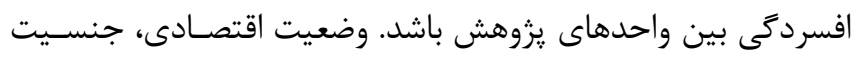

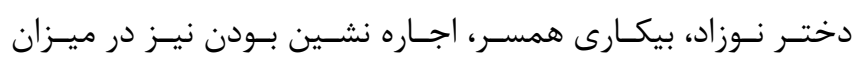

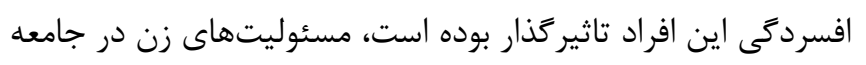

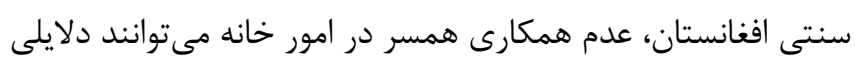

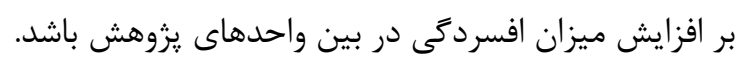

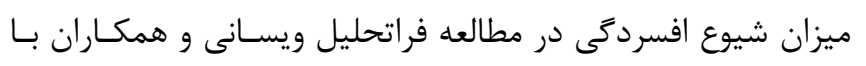

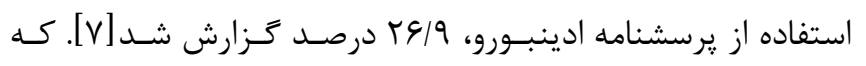

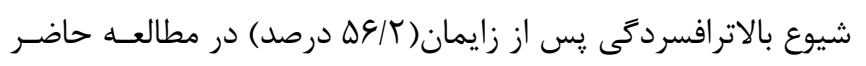

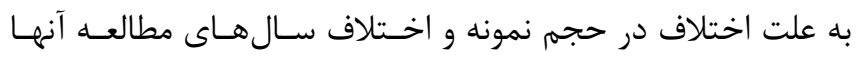

\section{بحث و نتيجه گيرى}

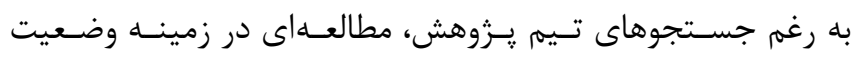

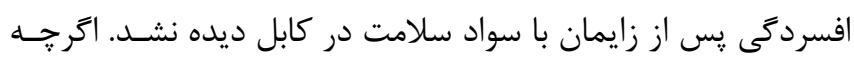

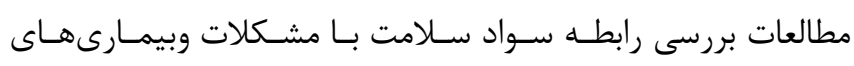

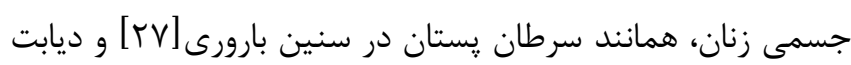

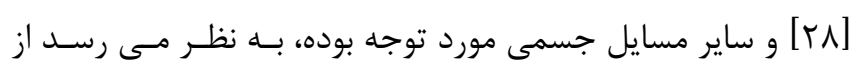

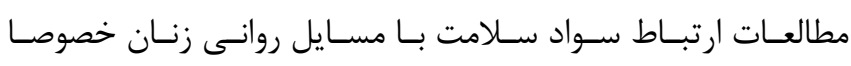

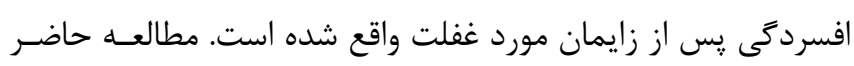

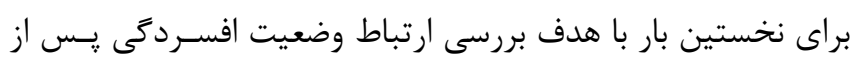

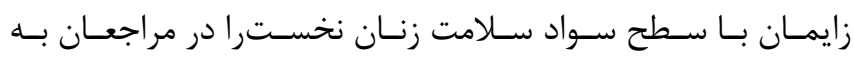

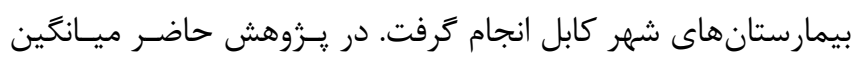

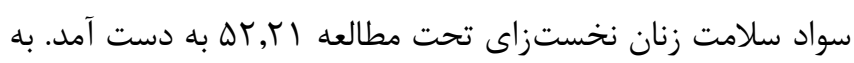

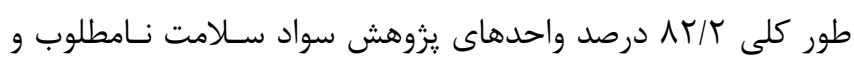

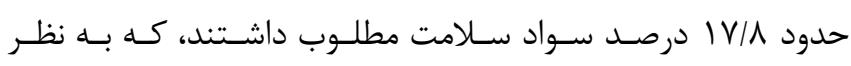

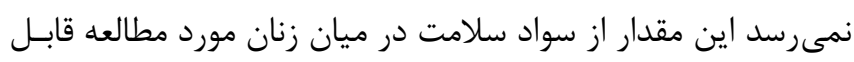

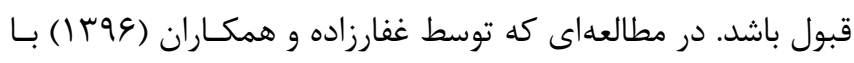

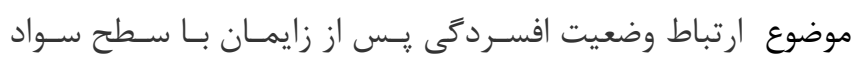

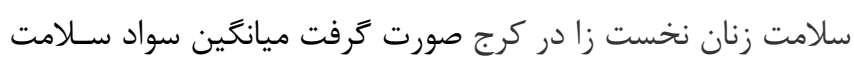

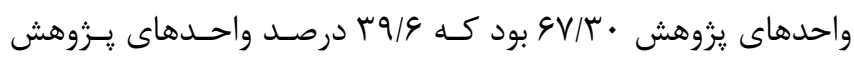

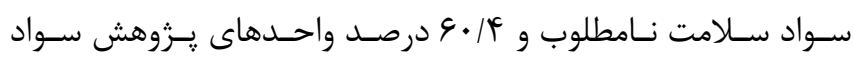

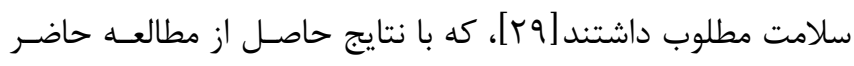

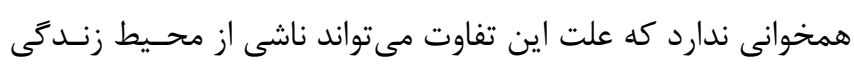

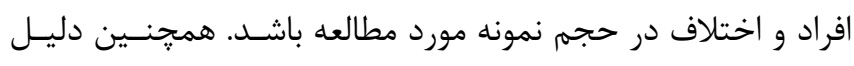

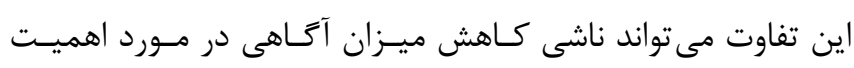

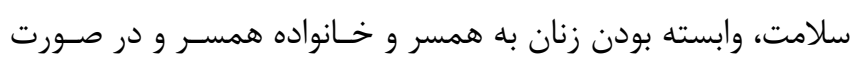

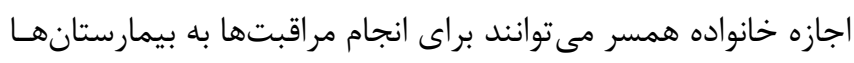

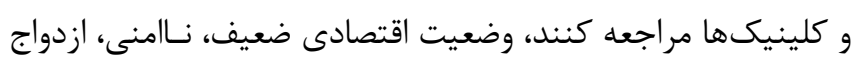

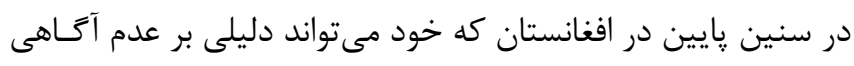

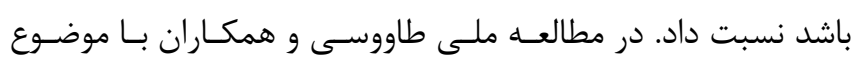

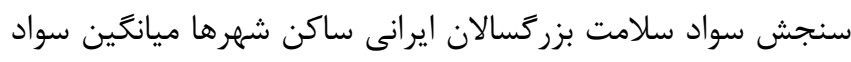

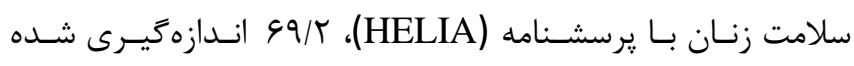

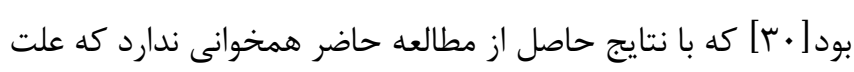

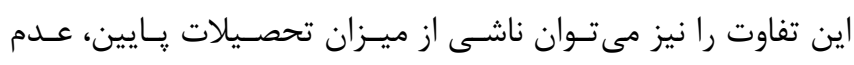

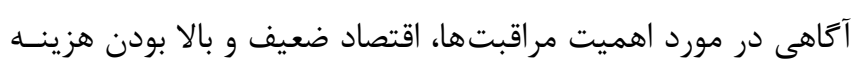

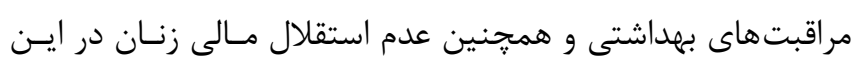

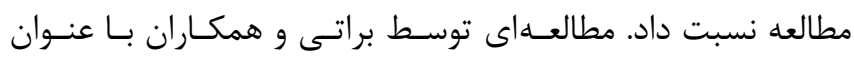


خطر و ارجاع و هدايت آنان بـه مراكـز ذى صـلاح مسـئول سـلامت نـات روان زنان باردار بنمايد. همجنين در اين راستاو و با توجـهـ بــه نتـايج

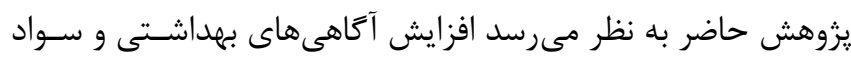

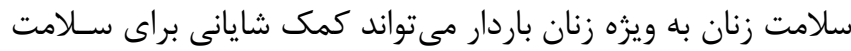

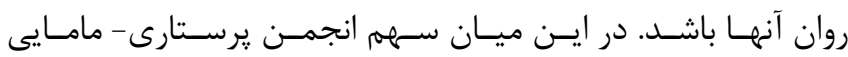

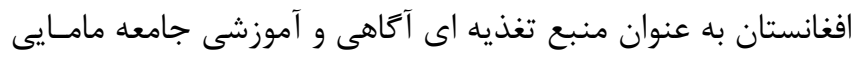

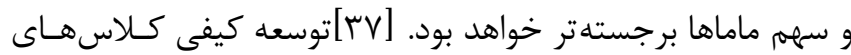

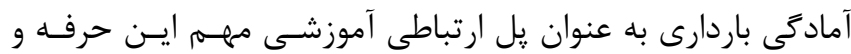

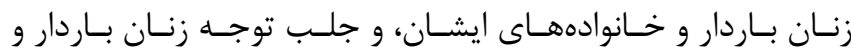

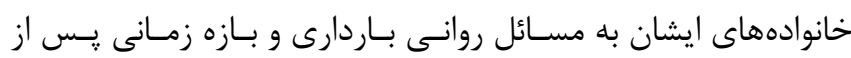
زايمان در كنار مسائل بهداشت جسمى باردارى براى كاهش شـيوع

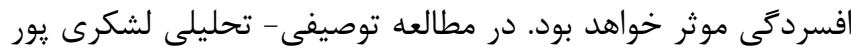

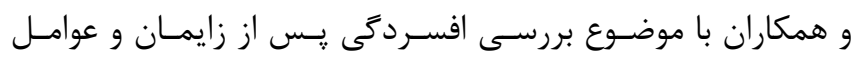

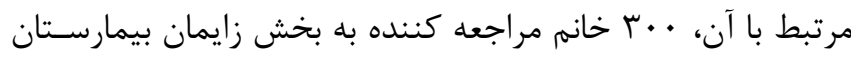

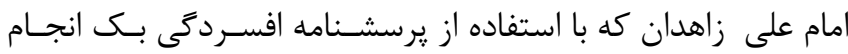

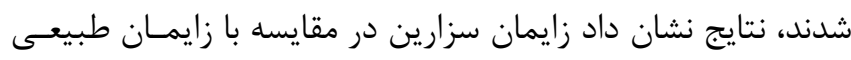

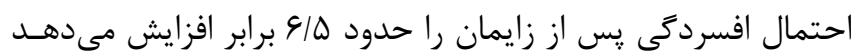

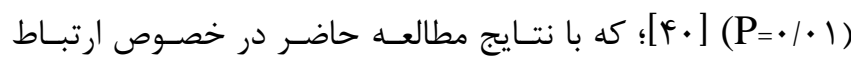

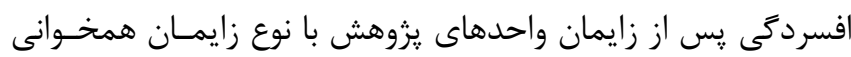
ندارد. علت اين تفاوت مى تواند ناشى از اين باشد كه ميزان زائ زايمـان

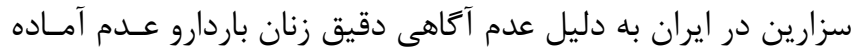

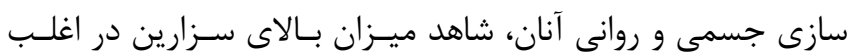
زنان باردار در ايران هستيم.

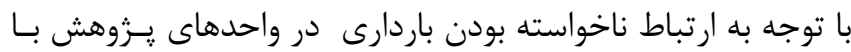

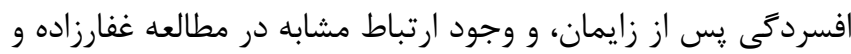

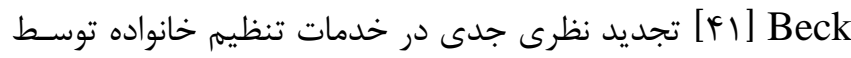

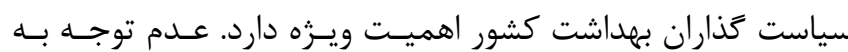

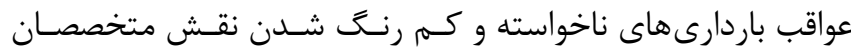

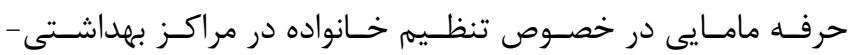

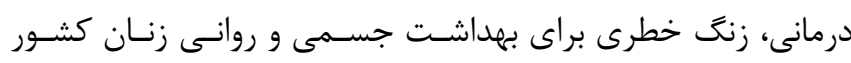

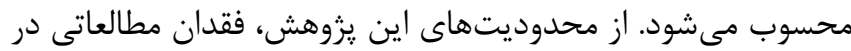

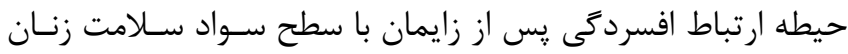

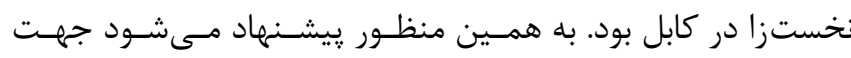
تعيين دقيقتر ارتباط افسردىى پِ از زايمان و سطح سواد سلامت

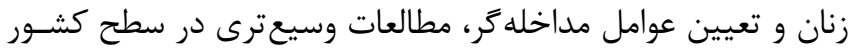

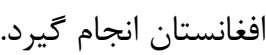

(I (IVG - I rMA ) در شهرستان قم و با يرسشنامه افسردگى يـس از زايمـان ادينبـورو،

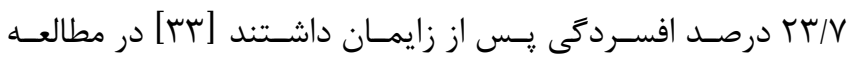

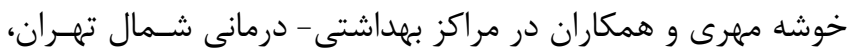

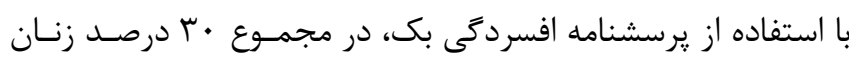

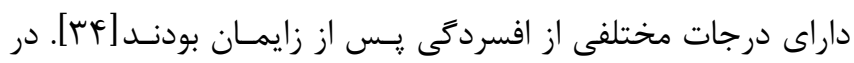

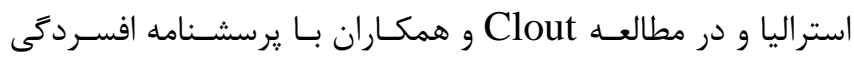

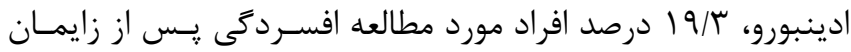

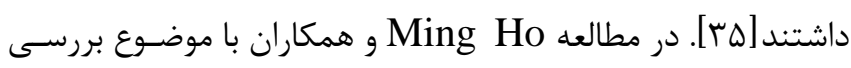

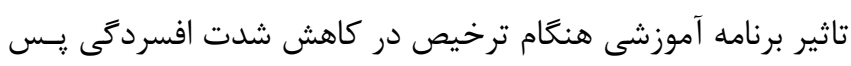

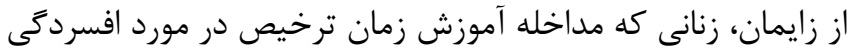

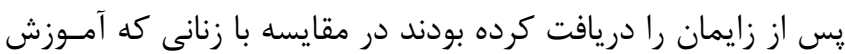

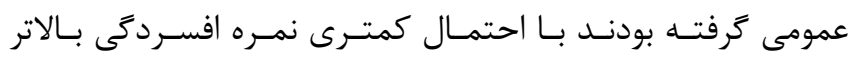

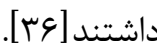

نتايج يزوهشهاى قبلى نشان داده است كه نه تنها وضعيت اشـتغال

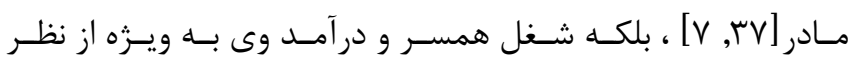

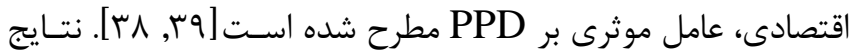

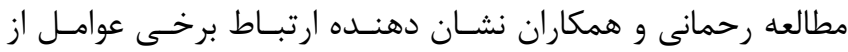

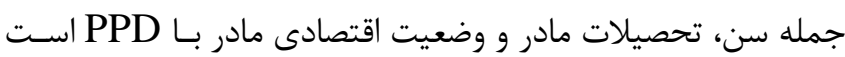

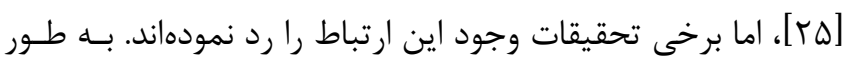
مثال خوشه مهرى و همكاران به اين نتيجه رسيدند كه بين اختلال

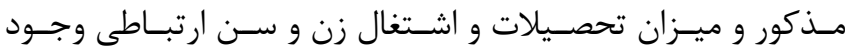

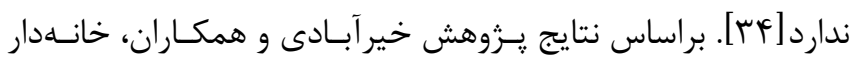
بودن مادر، از عوامل تاثير كذار بر PPD است، اما تحصيلات مـادر و و

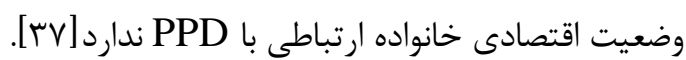

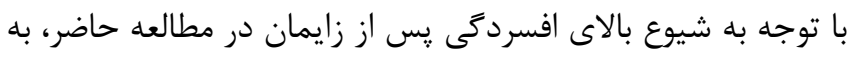

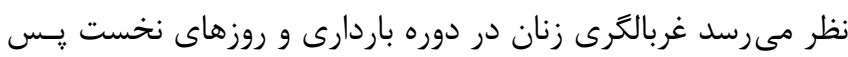

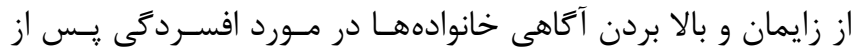

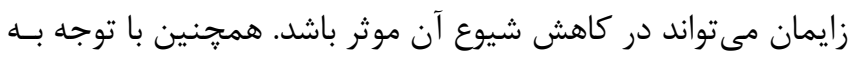

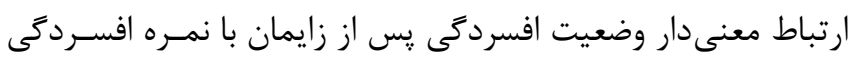

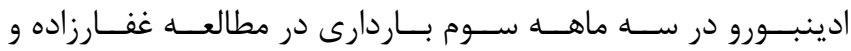

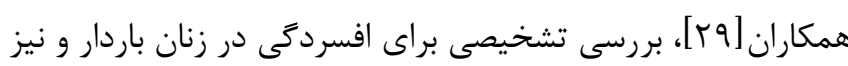

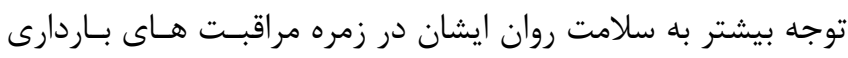

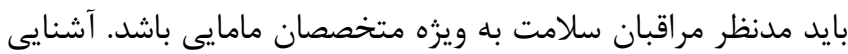

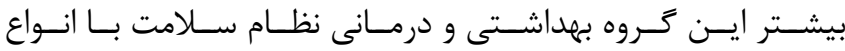

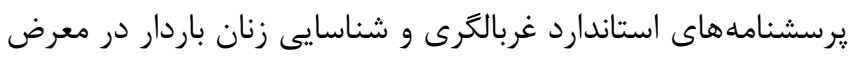




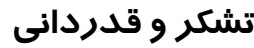

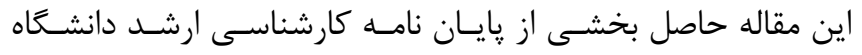
تربيت مدرس و با همكارى وزارت بهداشت كشـور افغانسـتان انجـام

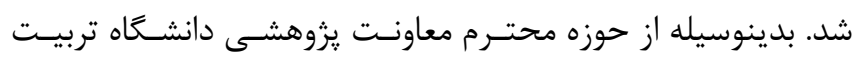

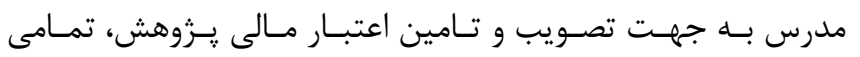

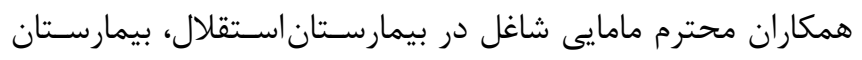

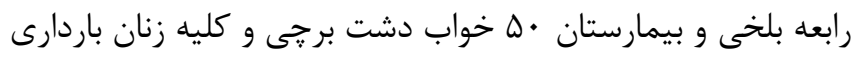

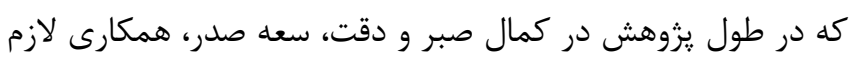
را داشتند، تشكر و قدردانى به عمل مى دى آيد.

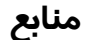

1. Lau Y, Htun TP, Kwong HKD. Sociodemographic, Obstetric Characteristics, Antenatal Morbidities, and Perinatal Depressive Symptoms: A Three-Wave Prospective Study. PLoS One 2018;13: e0188365

2. Darcy JM, Grzywacz JG, Stephens RL, Leng I, Clinch CR, Arcury TA. Maternal Depressive Symptomatology: 16-Month Follow-up of Infant and Maternal Health-Related Quality of Life. The Journal of the American Board of Family Medicine 2011; 1:24249-57

3. De Tychey C, Briançon S, Lighezzolo J, Spitz E, Kabuth B, De Luigi V, Messembourg C, Girvan F, Rosati A, Thockler A, Vincent S. Quality of Life, Postnatal Depression and Baby Gender. Journal of Clinical Nursing 2008;17:312-22

4. Sankapithilu GJ, Nagaraj AK, Bhat SU, Raveesh BN, Nagaraja V. A Comparative Study of Frequency of Postnatal Depression among Subjects with Normal and Caesarean Deliveries. Online Journal of Health and Allied Sciences 2010; 30:9

5. Webster J, Nicholas C, Velacott C, Cridland N, Fawcett L. Quality of Life and Depression Following Childbirth: Impact of Social Support. Midwifery 2011;27:745-9

6. Alshikh Ahmad H, Alkhatib A, Luo J. Prevalence and Risk Factors of Postpartum Depression in the Middle East: A Systematic Review and Metaanalysis. BMC Pregnancy Childbirth 2021;21:542

7. Veisani Y, Sayehmiri K .Prevalence of Postpartum Depression in Iran - A Systematic Review and Meta-Analysis. The Iranian Journal of Obstetrics, Gynecology and Infertility 2012; 15: 21-29

8. Segre LS, Davis WN. Postpartum depression and perinatal mood disorders in the DSM. Postpartum Support International 2013; 3:1-6

9. Da Costa D, Dritsa M, Rippen N, Lowensteyn I, Khalife S. Health-Related Quality of Life in Postpartum

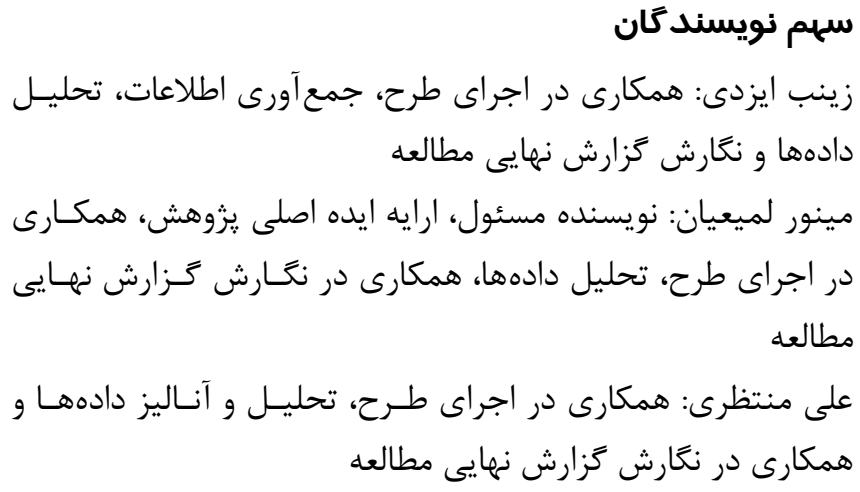

Depressed Women. Archives of Women's Mental Health 2006;9:95-102

10. Wolman WL, Chalmers B, Hofmeyr GJ, Nikodem VC. Postpartum Depression and Companionship in the Clinical Birth Environment: A Randomized, Controlled Study. American Journal of Obstetrics and Gynecology 1993;168:1388-93

11. O'hara MW, Swain AM. Rates and Risk of Postpartum Depression-A Meta-analysis. International Review of Psychiatry 1996;8:37-54

12. Mclearn KT, Minkovitz CS, Strobino DM, Marks E, Hou W. Maternal Depressive Symptoms at 2 to 4 Months Postpartum and Early Parenting Practices. Archives of Pediatric Adolescent Medicine 2006; 160: 279-84

13. Josefsson A. Postpartum Depression:

Epidemiological and biological aspects [dissertation]. Linköping University, 2003

https://pubmed.ncbi.nlm.nih.gov/11207491/

14. Bolak Boratav H, Toker Ö, Küey L. Postpartum Depression and Its Psychosocial Correlates: A Longitudinal Study among a Group of Women in Turkey. Women Health 2016;56:502-21

15. Zhang R, Chen Q, Li Y. Study for the Factors Related to Postpartum Depression. Zhonghua Fu Chan Ke Za Zhi 1999;34:231-3

16. George C, Kumar A, Girish N. Effectiveness of a Group Intervention Led by Lay Health Workers in Reducing the Incidence of Postpartum Depression in South India. Asian Journal of Psychiatry 2020;47:101864 17. Chaaya M, Campbell OM, El Kak F, Shaar D, Harb H, Kaddour A. Postpartum Depression: Prevalence and Determinants in Lebanon. Archives of Women's Mental Health 2002;5:65-72

18. Rahmatollahi N K-kA, Mansoor L, PourEbrahim TJCH. Pravalance and Risk Factor Associated with Postpartum Depression in Women Consulting in Primrey care, 2008. http://hdl.handle.net/11086/14201 
19. Olfson M, Marcus SC, Druss B, Elinson L, Tanielian T, Pincus HA. National Trends in the Outpatient Treatment of Depression. Jama 2002 9; 203-9

20. Yousefzade S, Pilafkan J, RouhiBalasi L, Hosseinpour M, Khodadady NJJoOH, Epidemiology. Prevalence of Mental Disorders in the General Population Referring to a Medical Educational Center in Rasht, Iran. Journal of Occupational Health and Epidemiology 2014;3:32-6

21. Don Nutbeam, Ilona Kickbusch, Advancing Health Literacy: A Global Challenge for the 21st Century. Health Promotion International 2000;3: 183-184

22. Commission on Social Determinants of Health. (2008). Closing the Gap in a Generation: Health Equity through Action on the Social Determinants of Health: Final Report: Executive Summary. World Health Organization. https://apps.who.int/iris/handle/10665/69832

23. an der Heide I, Wang J, Droomers $M$, Spreeuwenberg P, Rademakers J, Uiters E. The Relationship between Health, Education, and Health Literacy: Results from the Dutch Adult Literacy and Life Skills Survey. Jounal Health Commun 2013;18 1:172-84

24. Shieh C, Halstead JA. Understanding the Impact of Health Literacy on Women's Health. Scholarly articles for Journal Obstet Gynecol Neonatal Nurs 2009;38:601-10

25. Ferguson B. Health Literacy and Health Disparities the Role They Play in Maternal and Child Health. Nursing for Women's Health 2008; 12:288- 298

26. Peyman N, Abdollahi M. The Relationship between Health Literacy and Self-Efficacy of Physical Activity in Postpartum Women. Health Literacy 2017; 512 [Persian]

27. Lamyian M, Moghaddam-Banaem L, Setoodeh SM. Health Literacy in Iranian with Breast Cancer. Austin Public Health 2016; 1:1002

28. Khosravi A, Kh A, Sh A, Tahmasbi R. Health Literacy Levels of Diabetic Patients Referred to Shiraz Health Centers and Its Effective Factors. Health Info Manage 2015;12:205

29. Ghaffarzadeh Khoei M, Lamieian M, Lotfi R, Montazeri A. The Relationship between Postpartum Depression and Health Literacy Levels of Nulliparous Women. Payesh 2018; 797-805 [Persian]

30. Tavousi M, Montazeri A, Haeri Mehrizi A, et al. Health Literacy in Iran: finding from a national study. Payesh 2015; 15: 95-102[Persian]
31. Afshari M, Barati M, Bijari S, Taherpour M. Investigating the Relationship Between Health Literacy and Quality of Life of Famenin Employees: a CrossSectional Study. Health Literacy 2018, 46-55

32. Tehrani Banihashemi SA, Haghdoost AA, Amirkhani MA, Alavian SM, Asgharifard H, Baradaran H, Barghamdi M, Parsinia S, Fathi Ranjbar S. Health Literacy and the Influencing Factors: A Study in Five Provinces of Iran. Strides in Development of Medical Education 2007;4:1-9

33. Khorramirad A, Mousavi Lotfi M, Shoori Bidgoli A. Prevalence of Postpartum Depression and Related Factors in Qom. Pajoohandeh Journal 2010; 15: 62-66 [Persian]

34. Khooshemehry G, Shariati F, Naserkhaki V. Prevalence of Postpartum Depression and the Factors that Decides in North of Tehran. Avicenna Journal of Nursing and Midwifery Care 2012;3:59-69

35. Clout D, Brown R. Socio-demographic, pregnancy, obstetric and postnatal predictors of postpartum stress, anxiety and depression in new mothers. Journal of Affective Disorders 2015; 188: 60-67 36. Ho S-M, Heh S-S, Jevitt CM, Huang L-H, Fu Y-Y, Wang L-LJPe, et al. Effectiveness of a Discharge Education Program in Reducing the Severity of Postpartum Depression: A Randomized Controlled Evaluation Study. Journal of Patient Education Counseling 2009;77:68-71

37. Kheirabadi G, Sadri S, Abedi Z, Velayati E. Postpartum Depression and Related Factors in Rural Areas of Najafabad, Iran. Journal of Behavioral Science Research 2015;13:555-61

38. Rahmani F, Seyedfatemi N, Asadollahi M, Seyedrasooli A. Predisposing Factors of Postpartum Depression 2011;24:78-87

39. Stepanikova I, Kukla LJM, journal ch. Is Perceived Discrimination in Pregnancy Prospectively Linked to Postpartum Depression? Exploring the Role of Education 2017; 21:1669-77

40. Lashkaripour K, Bakhshani NM, Hokmabadi S, Sajjadi S, Safarzadeh S. Postpartum Depression and Related factors: A 4.5 months study 2012. The quarterly Journal of Fundamentals of Mental Health 2012;13: 404412 [Persian]

41. Beck C. Predictors of Postpartum Depression: an update. Nursing Research 2001;50:275-85 